\title{
11 MEASURING THE SUSTAINABILITY OF A COMMUNITY SAFETY PROMOTION NETWORK: WORKING FROM THE INSIDE OUT
}

doi:10.1136/injuryprev-2012-040580e.11

${ }^{1} \mathrm{D}$ Hanson*, ${ }^{2} \mathrm{~K}$ McFarlane, ${ }^{2} \mathrm{P}$ Vardon, ${ }^{2} \mathrm{~J}$ Lloyd, ${ }^{1} \mathrm{R}$ Speare, ${ }^{3} \mathrm{D}$ Durrheim. ${ }^{1} \mathrm{James}$ Cook University, Australia; ${ }^{2}$ Oueensland Health, Australia; ${ }^{3}$ Hunter New England Health, Australia

Background While project sustainability is a mandatory piece of politically correct rhetoric, it is less often achieved. Mackay Whitsunday Safe Communities (MWSC) was developed using a capacity building model that consciously attempted to design sustainability into the network.

Aims/Objectives/Purpose This study sought to analyse the sustainability of MWSC by tracking the exchange of resources using Social Network Analysis (SNA).

Method A snowballing methodology was used to identify the MWSC and its external support network (ESN). Respondents were asked to identify the type and amount of resources they shared with other network partners.

Results/Outcome The study identified 168 members of the MWSC and its ESN. Thirty-five per cent of relationships did not share any resources; $47 \%$ shared in-kind resources, 54\% shared human resources and $15 \%$ shared financial resources. In 2004 MWSC accessed an estimated 6.5 full time staff equivalents and \$0.9 million Australian dollars. However, these resources were largely accessed through, and controlled by, the ESN. MWSC was rich in social resources, but considerable in-kind, human and financial resources were accessed through its ESN. The bridging relationships that connected MWSC to its ESN, more than half of which were maintained by six broker network facilitators, were the critical social asset required to access resources and thereby sustain network productivity.

Significance/Contribution to Field MWSC is an open network. Open social networks can never be totally self-sufficient. The ongoing productivity of a social network is dependant on its capacity to develop and maintain productive links with external partners. 